\title{
Pornography Addiction Challenge among the Youth: A Case Study of Highfield High Density Area, Harare
}

\author{
Tapiwa Zinyemba \\ Adventist University of Africa, Zimbabwe
}

\begin{abstract}
Exposure to pornography poses a serious challenge to youth all over the world. Several studies have noted that the vice often leads to various physical, mental and social challenges. These include negative feelings about oneself, distorted beliefs and perceptions about relationships and sexuality, isolation, addiction, increased aggression among others. In Zimbabwe, there appears to be a dearth in literature on pornography and how exposure to it affects an individual. Using the qualitative research methodology which included making use of in depth interviews, the paper sought to understand how youths in Highfield are exposed to pornography and how it has impacted on their lives. Findings show that the exposure to pornography and subsequent addiction is attributed to increased access to the internet, social media applications and platforms and electronic devices like mobile phones, laptops, tablets and personal computers where pupils can visit pornographic websites for viewing, downloading and sharing pornographic pictures and videos. The study recommends a multi-pronged theological approached where school administrators, teachers and parents and guardians coordinate and collaborate in educating the youths in the negative impacts of viewing pornography.
\end{abstract}

Purpose: Whereas pornography viewing amongst secondary school students and youth in Highfield location of Harare, Zimbabwe is a challenge, the paper seeks to document the factors prompting youths to engage in this practice. It attempts to how pornography is affecting young people in developing countries like Zimbabwe. Above all the study will unpack the Biblical and theological reflections on pornography and what preventative mechanisms can be put in place to ensure total deviation from the practice.

Findings: Findings revealed that exposure to viewing pornographic material is prevalent in Highfield. The researcher's interactions as a pastor with youths in the area, the questionnaires, in-depth interviews, and focus groups discussions held during the course of the study showed the prevalence of access and addiction to pornographic material among the youths.

Key Words: Arousal, Explicit, Erotic, Abstain, Exposure, Prevalence

\section{INTRODUCTION}

$\mathrm{P}$ ornography has been defined differently by several scholars but the mostly used definition describes pornography as sexually explicit materials intended to arouse (McKee etal, 2019). Further, the Merriam Webster dictionary (2021) defines pornography as, "the depiction of erotic behavior (as in pictures or writing) intended to cause sexual excitement." The CARA article (2019) also defines pornography as "the explicit representation of sexual activity in print or on film to stimulate erotic rather than aesthetic or emotional feelings."

There are so many common challenges associated with pornography exposure. Quadara etal (2017) suggests that pornography is directly linked to unsafe health practices such as none use of condoms during sexual intercourse, unsafe anal and vaginal sex. They further note the possible existence of gaps between expectations and reality that can produce sexual uncertainty about sexual beliefs and values which may result in sexual dissatisfaction, anxiety and fear.

Relationships can also be significantly affected due to pornography. The continued rise of internet access and use across the globe appears to have increased pornography viewing (Cooper, Boies, Maheu \& Greenfield, 1999). Exposure to pornographic material via the internet has been linked with negatively influencing people within the family set up, workplace and in the community. Manning (2006) also suggested that the family life of married people will be negatively affected.

Pornography is strongly linked to masturbation and the latter is a challenge that may cause sexual dysfunction among men erectile dysfunction can be defined as the inability to get or keep an erection firm enough to have sexual intercourse (Biggers, 2019). Bush (2018) argue that some young married couples may face a number of challenges in their sexual life due to differing sexual expectations. This is because pornography viewing gives an impression that what is being acted in the erotic movies can be done in real life. The background information about the drugs taken, the creation and duration of the sex scenes are hidden from the public. Resultantly, partners expect more from their husbands or wives based on what they see on pornographic movies which is far from reality.

The paper will argue that pornography exists within a broader sociocultural context in which stereotypes about gender, sexism, sexual objectification and violence supportive attitudes are also at play. Therefore, youth and young people need to abstain from viewing pornography as it leads to a vicious web of addiction. They should wait until they are married to enjoy sex and its marital benefits.

\section{LITERATURE REVIEW}

Identifying the Problem of Pornography 
Pornography exposure and addiction are prominent among the youthful as well as adult population across the globe. The availability and affordable internet and smart mobile devices make accessing pornographic content easy for young people. Despite many countries having laws prohibiting the viewing and distribution of pornographic content, the viewing and distributing of pornography continues to rise. In fact, the pornography business is one of the most thriving global businesses. A study by the Barna group (2016) found that males dominate statistics related to pornography viewing but current trends show an increased prevalence among females.

Studies show that women also view pornographic material for a plethora of reasons, such as curiosity, loneliness, boredom, rejection, stress and dissatisfaction among others (Simpson, 2018). This proves that this issue cuts across gender. However, studies by Bimber (2000) found that males visit pornographic websites more than females. The same study also found that the production of pornography movies is male dominated. The study focusses on the challenges of exposure and addiction to pornography by youths of school going age, that is, from the ages of 13 to 18 years. Although this paper focuses on youths, the problem of pornography is common among adults.

\section{The Sources of Pornography}

There are many sources of pornographic content and material. The sources can be in the form of print media such as books, magazines, postcards, paintings and drawings. Electronic media sources of pornography include films, videos, animations, websites and video games. The latter are affordable and easily accessible by the youths as there are limited restrictions to accessing pornographic materials. The COPS FY (2010) notes that access to internet allows images and digitalized movies to be reproduced and disseminated to tens of thousands of individuals at a click of a button. The internet is the most preferred medium of distributing and disseminating pornographic material because of its universal coverage and the anonymity it brings to the distributors (COPS FY, 2010).

\section{Views and Use of Pornography among Youth}

Flory (2016) views pornography as a widespread public health issue that has widely accepted explicit images and distorted sexual behavior and wreaking havoc on society, harming minds, bodies, relationships, and souls. Exposure and addiction to pornography has been linked to several sexually related problems among the youth. These include pre-marital sex, masturbation and depression Barna's (2015) study, found that thousands of American youths and adults were living in an environment where porn is more acceptable and more ubiquitous than ever before.

McDowell (2015) found that there are varied opinions about what constitutes pornography among the youths. Some youths do not appreciate the negative consequences of pornography viewing while others are ashamed about the practice and in worst cases, battling pornography addiction. According to Mc Dowell's study in the United State of America, one in three youths attempts to view pornographic content at least once a month. McDowell (2015) attributes this behavior to the environment the youths live in which is hyper-sexualized by media culture where sex related images and themes are used to market some products. This exposes the young people to sex related content at time unintentionally however with adverse effects on the youths. Further views from McDowell (2015) posits that age, gender, and faith practice are the three biggest factors in frequent porn use. He further asserts that young adults (18-24 years), view more porn and they are less likely to say it is bad for society.

\section{Effects of Pornography Use}

The use and viewing of pornography have many negative effects on the individual, family, and society. Duffy et al (2016) asserts that the effects of pornography differ from one individual to another and studies have shown that the effects have an effect on sexual relationships. This may cause marital challenges among married couples.

The National Center on Sexual Exploitation (2016) argues that "pornography is a social toxin that destroys relationships, steals innocence, erodes compassion, breeds violence, and kills love. The researcher concurs with this view because he has come into contact with family and church members battling pornographic addiction. For those seeking mental and spiritual purity, pornography should not be tolerated. Sabina et al (2008), reported that the degree of exposure to a condition is characterized by abnormal sexual desires, typically involving extreme or dangerous activities and departing from usual or accepted standards, especially in social or sexual behavior by young people.

Shelley Lubben (2011), a former porn actress described the effects of engaging in pornography acting and later on her deliverance from the industry. She testified that a teenage boy sexually violated her at age 9 and this unfortunate encounter triggered her entry into the pornographic business at the tender age of 18. At the age of 19, she had a baby out of wedlock from a client. When she was 24 years old, she was a fully-fledged porn star and was earning an average of US\$2000 per movie. Her intention was to be famous and make a name for herself at the same time earning a lot of money. Unfortunately, she became a drug addict and contracted various sexually transmitted infections during her career as a porn star. Eventually, Shelley was bitter and angry with herself. To her, pornography is the devil's territory.

Ellen G White (2001) saw that "many young people are eager for books and they can just read everything they can obtain without selecting what is good. They will meet exciting love stories and impure pictures that have a corrupting influence." After much perusal and viewing photographs of females in a state of nudity, which is frequently speculated for 
sale, Ellen White then concludes that their imaginations become defiled.

The Barna group (2016) views pornography as having the potential to psychologically harm viewers, affect their future sexual performances as well as affect how they will view the opposite sex even in marriage. The group further contends that pornography damages people's sexual performance which leads to sexual problems like premature ejaculation and erectile dysfunction (Barna, 2016).

Marni (2020) concurs with the above assertion adding that pornography could lead couples to suffer guilt and mistrust, which can tear marriages apart. She further states that porn can cause one spouse to withdraw from the 'real' relationship because of instant gratification being obtained from a fake online pornographic relationship. Apart from losing sexual satisfaction, a spouse whose partner is addicted to pornography may feel disrespected and insecure, concluding that they are not good enough for their partner which creates a wedge in the marriage. Antonia et al (2017) added that pornography could act as a trigger to short-term gains but certainly not in the long-term marriage system. Covenanteyes (2009) noted that pornography may wrecks someone's libido when making love or causes someone to be lazy sexually

According to Zawn (2018) pornography may lead to a spouse failing to get aroused by the partner, it turns love into a foreign concept, makes regular sexual intercourse seem boring, and making the spouse not be tender in a relationship. Porn may cause selfishness by ignoring the spouse's needs and focusing on getting what you want instantly. It can give the spouse a warped view of what is attractive since sex is meant to bond the spouse physically, emotionally, and spiritually (Tolovehonorandvacuum, 2016).

In studies conducted on various ways which trigger porn consumption, I was touched by the fact that the teens that access online pornography may dangerously enter into the world of private sexual exposure that can alter their expectations for healthy future relationships and this can end up exposing them to risky sexual relationships. They further allege that this secrecy behavior will cultivate so many painful experiences by the pornography user. This assertion agrees with my sentiments as 1 have seen painful experiences in the members 1 lead in the community. Some males would experience the erectile dysfunctions among other challenges.

One writer in the Indian magazine (2016) argues that "pornography has great power, influence, and many effects which can help enhance the sexual act between married couples who may be ignorant about experimental sex moves. It can further come to their rescue by helping them to master new techniques and ways to please them." In any case, both husband and wife must agree on what to view and what not to view. People need to understand how porn actors are often slaves and suffer a great deal since porn acting is mostly to make money (Indian Magazine 2016). However, the act of sexual intimacy has no prescribed formular on what to do and what not to and how to do it, it is exploratory and depends on personal preferences of the parties involved. These arguments in favor of pornography do not hold water for there are so many ways to mentor young people through premarital counseling in various ways before engagements and solemnization of marriages.

One government minister from the United Kingdom once said, "in every second 3000 dollars is gained through the sale of porn videos, 28000 internet users are viewing pornography every second and 372 per second are typing adult searches for porn." (Davidson, 1994). This is a silent pandemic from a moral perspective, which may run head-tohead with the leading players being the young people as surveyed by the American study.

Predictions by faithandsafety (2016) are that pornography viewing will forever remain a global problem which will not be easily dealt with. They estimated that by 2017, 250 million people would be accessing adult content on their mobile devices because mobile devices have become increasingly personal. As a pastor, I have noticed that many church members have more than one mobile phone. This means youths in all places around the globe are vulnerable to pornography.

The study argues that accessing pornography has been made easier by the upsurge in ICT use. The technological realities of smartphones and high-speed internet have fundamentally changed the landscape of pornography and ushered it into the cultural mainstream where it enjoys increasingly widespread acceptance (Barna, 2016). With the above scenario in mind, it, therefore, coerces me and other local leaders to look at reality. Simpson, who is a senior psychology student at Andrews University in Berrien Springs, Michigan, United States, said she was glad when church leaders are willing to look at reality (Adventist Review, 2013). Theologians and church leaders should not shun away from addressing sensitive issues like pornography viewing and distribution.

\section{Biblical and Theological Reflection on Pornography}

While there might be no direct mention of pornography in scripture, the Bible speaks of related themes of adultery and sexual immoral activities. The Bible gives warning and counsel regarding moral decay which comes from pursuing desires of the flesh. One text had to ask a question that, "Or do you not know that wrongdoers will not inherit the kingdom of God? Do not be deceived: Neither the sexually immoral nor idolaters nor adulterers nor men who have sex with men" (1 Cor 6:9). From a biblical perspective, sex must be done within the institution of marriage and same sex intimacy is prohibited according to the above text. Pornography falls within the context of sexual immorality and the bible notes that those who embark in this vice do not 
qualify for God's Kingdom because they will be morally depraved.

Professed followers of God should turn away from viewing anything that contaminates them. Job made a covenant with his eyes not to look lustfully young women (Job 31:1). When one views pornography, lust is involved, adultery takes precedence and one may end up masturbating. This is a long list of sexual sins which the Lord finds detestable. Jesus Christ also suggested that anyone who would look at a woman lustfully would be committing adultery in his heart (Matt 5:28). The Psalmist requested the Lord to turn his eyes away from worthless things and to preserve his life according to God's word (Psalm 110:37). All these texts are encouraging people to abstain from viewing among other things, pornographic material.

The Bible through the Apostle Paul encourages people to give glory to God in all they do: "... whatever you do, do all to the glory of God." (1 Cor 10:31) Does viewing pornography give glory to God? is a pertinent question worth answering. The porn phenomenon study (Barna: 2016) exposes the breadth and depth of porn's impact and shows that the Christian community can no longer ignore pornography's effects on the minds and hearts of the next generation. When we look and listen to the statistics found in our world concerning the issue of pornography, one becomes so amazed. One article Webroot (2018) argues that about 200000 Americans are classified as porn addicts. They further allege that 40 million American people regularly visit porn sites indicating that about $35 \%$ of all internet downloads are related to pornography. As access to pornography increases, making inroads even into the church, 1 have observed that it is an issue that is not normally discussed within the church. This poses a problem because youths end up looking for solutions on their own, some of which may destroy them.

Today, too many people do not see the pornography tidal wave bearing down on all cultures, religions, gender, and people. How then does a young person stay pure and not be violated when using the Internet, watching a movie, TV sitcom, or going through the checkout line at the store? In the counsel to young people about pornography and the mind, White (2001) encourages young people to avoid reading and watching material that triggers impure thoughts. She encourages youths to always cultivate moral and intellectual powers. These noble powers should not become weak and be characterized by these unacceptable practices.

\section{Proposed Preventative Programs to Pornography}

There is a common statement, which says prevention is better than cure which I subscribe to. Training and educating young people is very important. The Bible encourages parents to, "train up the young in the ways they should move so that when they get old, they may not depart from them" (Prov 22:6). The Health and Human Health services (2016) have various programs on the prevention of pornography and premarital sex addiction. The programs include but are not limited to having school-based programs on sexuality, family-based programs which strengthen the relationships of parents and youths. The family programs enhance parenting skills in nurturing, setting limits, and improving family communication. Some preventive programs can be adolescents' substance refusal like drugs and alcohol, which may lead to pornography and premarital sex addiction. College and school awareness programs should be carried.

\section{RESEARCH METHODOLOGY}

The research employed a qualitative research methodology. Kumar (2011:47) defines qualitative approach as "a planned subjective procedure used to explain life's experiences and circumstances to give them meaning." With the qualitative approach, one is able to critically examine people's responses to dissimilar life situations in a bid to enhance, as well as grasp an understanding of their experiences (ibid). Creswell (2013) concurs with this view, further asserting that a qualitative methodology plays a pivotal role in circumstances where the researcher attempts to define situations that cannot be measured in numerical terms. Creswell further states that the qualitative approach's aim is to portray or report a situation based on peoples' views, thoughts and opinions. In other words, the qualitative approach assisted the researcher to come to terms with the issue of pornography and how it affects young people in Zimbabwe. This methodology was preferred because the paper's research questions intend to unearth respondents' perceptions and experiences. These realities are only extracted from the minds of the participants qualitatively, informed by the philosophical assumption that reality is in the mind of an individual concerned.

The study was conducted in Highfield residential suburb in Harare. The population of the study included five secondary schools namely, Mukai Secondary School, Highfield High 1 School, Highfield High 2 School, Mhuriimwe Secondary School, and Kwayedza Secondary School and the school teachers of each of these schools. Each of the schools has six grades, that is form 1 to form 6 . The five secondary schools are government schools under the Ministry of Primary and Secondary Education in Zimbabwe. The five schools have a combined enrolment of eight thousand two hundred (8200) pupils. Participants in the study were purposively selected. This is a sampling type that involves the deliberate selection of a participant based on his or her capabilities or qualities in relation to the study at hand (Saunders, Lewis and Thornhill, 2016). This technique is nonrandom and needs not underlying theories or a specific number of participants. Loosely speaking, the researcher makes a determination of what needs to be known in his study then makes an attempt to find individuals who are capable of adequately providing him with the requisite information that he requires based on their knowledge or experience (ibid). 
This technique was adopted in this study to ascertain and select information-rich cases so as to make effective use of available resources. Using information and advice from literature, the researcher noted that this technique was the most appropriate for the study at hand as it specifically needs to interview people who are aware of the effects of pornography either through direct participation or observing the impacts via peers. Therefore, 6 teachers were selected from each, in total, 30 teachers were selected and interviewed for the study. A sample size of 400 pupils was selected for the study. According to Gay (1987) for a population range of 5000-10000 respondents, a sample size of 3\% is appropriate. For this study, a sample size of 400 is $4.8 \%$ of the population which is more than the recommended sample size. The grades were used as strata for the study. Each strata comprised of two grades from each school. Form 1 and Form 2 formed a strata, form 3 and form 4 formed another strata and form 5 and form 6 formed the final strata. A total of 30 pupils were systematically selected from strata of form 1 and form 2 and form 3 and form 4 from each of the five schools. The pupils comprised an equal number of males and females. A total of 20 pupils were systematically selected for the form 5 and form 6 strata. For all the 5 schools the form 1 to form 4 grades have the most students compared to the form 5 and six grades. Data were collected using questionnaire survey and focus group discussions. A total of 400 questionnaires were distributed according to the strata specified. Pupils for the focus group discussion were purposive selected from pupils who had been selected through the first stage of sampling. Ten pupils were selected for the focus group discussion in each strata from each school.

In-depth interviews were used as a data collection method. An in-depth interview is a two-way conversation initiated by the interviewer for the purpose of obtaining research information and is focused on the content specified by the objectives of the systematic description, prediction, and explanation Creswell (2013). In-depth interviews were conducted with teachers, students, parents and guardians of high school going age in Highfield. The researcher made use of interview guides as an instrument for collecting data under this data collection method. An interview guide can be helpful to researchers who are conducting semi-structured in-depth qualitative interviews. It is a list of questions that are asked to participants during the interview. The order of the questions and the level of degree to which one diverges from the set of a defined list of questions will vary based on the type of interview the researcher chooses to conduct. The data analyzed thematically where themes were developed based on the questions asked and coded.

A study of this nature was sensitive because it involved a theme on sexuality among minors. According to Zimbabwean Laws any person below the age of 18 years is considered a minor and cannot be exposed to certain issues with the consent of an adult or a higher authority. In order to gain entry into the research setting and conduct research with minors, the research applied for ethical clearance from the Adventist University in Africa where he is a Doctor of Ministry student, the Ministry of Primary and Secondary Education in Zimbabwe which is the parent ministry for primary and secondary schools and the school authorities. The ethics clearance application specified the purpose and objectives of the research and methodology to be used. Most importantly it explained that the researcher, after being granted permission, would seek the consent from the pupils to be interviewed and also would protect the identity of the pupils by using code names and pseudonyms instead of their real names. Further, the researcher assured the respective authorities and respondents that the data collected would solely for academic purposes only.

\section{RESULTS AND DISCUSSIONS}

The study was conducted in five secondary schools in Highfield suburb of Harare. Highfield is one of the oldest suburbs in Harare and Zimbabwe. Highfield was established in the 1930's by the then Southern Rhodesia Colonial Government as a suburb to house the black labourers for the Willowvale industrial area. After independence in 1980 Highfield has continued to grow in terms of population. Like most neighborhoods in developing countries, Highfield has a wide population pyramid base, comprised of the youthful population below the age of 30 years. Children and youths with ages ranging from 13 years to 21 comprise the largest population group. Where there is rapid population growth and incidences of urban poverty, morale decay is bound to happen. Sexual immorality and drug abuse are among the vices experienced in Highfield. As such, in an attempt to understand the motive behind the sexual activities among young people, the study looked at the issue of pornography viewing among students at 5 secondary schools in Highfield. Out of the 400 questionnaires distributed to pupils in the six grades, that is form 1 to form 6 in the 5 secondary schools in Highfield, 270 questionnaires $(67 \%)$ were completed and returned for analysis. The remaining 130 questionnaires were either not returned or returned incomplete, so they were discarded from analysis.

\section{Link between pornography and premarital sex}

School teachers indicated that pornography viewing is one of the most common activities that push students to engage in premarital sex. They noted that during teenage years, pupils begin to develop and mature sexually. A teacher who was a respondent in the study said:

It is also the same age that pupils in this age range begin to be curious about sex and their sexuality. During these ages, they engage in various sexual activities to satisfy their desires. They do this directly, through learning about reproduction through the education curriculum, social and religious teachings.

Other teachers argued that the rise of electronic media has ignited a surge in pornographic viewing which they 
assume also has a part in contributing to high sexual intercourse prevalence.

Electronic media exposes many students to limitless sexual. This coupled by peer pressure contributes to a high number of pornographic viewing and sexual activity among the youths.

Profile Age of Respondents

\begin{tabular}{|c|c|c|}
\hline Gender & & Percentage \\
\hline Female & 145 & $54 \%$ \\
\hline Male & 125 & $46 \%$ \\
\hline
\end{tabular}

The table above showed the number and percentage of the profile of the respondents and five secondary schools. From the table there are 54\% females and $46 \%$ male respondents. This automatically shows that there are more girls who participated in the study than boys. The table below shows which gender participated more in sexual activities.

Gender Participation in Sexual Activities

\begin{tabular}{|c|c|c|c|}
\hline Sexual Activity & Male & Female & Total \\
\hline Premarital Sex & 57 & 42 & 99 \\
\hline Masturbation & 113 & 49 & 162 \\
\hline $\begin{array}{c}\text { Viewing } \\
\text { Pornography }\end{array}$ & 199 & 54 & 253 \\
\hline Kissing & 177 & 68 & 245 \\
\hline Sexual romancing & 195 & 59 & 254 \\
\hline Intimate Hugging & 172 & 84 & 256 \\
\hline & & & \\
& & & \\
& & & \\
& & & \\
\hline
\end{tabular}

The responses from the interviews indicated that some students had engaged in more than one immoral activity.

\section{Proposed Solution to Pornography}

Based on my pastoral experience, members who suffer from pornographic addiction normally absent themselves from worship gatherings. Their participation in church life deteriorates and are less willing to accept the request to do so. The youth, who will be recovering from this crisis, will find it helpful to have hope in the Lord who is greater than themselves and their struggle.

Youth Mentorship: Youths grappling with pornographic addiction should be encouraged to consider talking with a mentor, pastor, spiritual leader, or someone who can help to guide and support him along the way. Jesus called the weary and the heavy-laden to go unto him for he promised them rest (Matt 11:28-29).

Churches need to create and utilize support groups with experts, for both the affected youths and the addicts, to "supplement therapy" as alluded by Laaser and Cisney (2007). Milrad (1999) encouraged, "Strong encouragement focusing on promoting open communication and awareness of youth experiences and feelings". In the journal Traylor Lovvon (2016) who authored the article Beyond the Checklist: Casting a Vision for Real Accountability, recommended the youths who are having this pornography challenge to be in the Accountability group.

Youth Support Groups: There should be support groups made up of willing teachers or mentors who understand the challenges associated with pornography so that they can assist young people battling with the problem.

Responsible use of the Internet: Another plan may be to encourage young people to abstain from immoral viewing of some websites until this problem has been wiped off from the client.

Relationship, Trust, and Respect Building: Relationships encompassed by trust and respect are important. Setting a counseling contract, which includes the promises of confidentiality but mentioning to the affected that when risk behaviors of causing harm to self are shown then 1 can break the confidentiality. The counselor needs to be open with the youth but telling constructive truth.

Training and counseling: of the young people and making them aware of the evils associated with pornography should be prioritized. When a young person is engaged in pornography, then there is a crisis, which needs standard treatment from the counselor's office. This crisis may affect the youth causing them personal trauma. Earl (1989) pointed out that, "a youth may be found on the internet watching pornography, seeing delivered emails or even to lose his job due to viewing pornography at work."

The counselor needs to work through the denial process by the youth since it is a coping mechanism. I will need not confront my youths but create friendship and an understanding relationship. When the rapport has been established, I may challenge the addicts' denial. There is a need for the addict to admit that they have a problem through personal humility. James in the Bible said God is opposed to the proud but He will give grace to the humble. The addict will need to surrender thoughts and ideas of old to follow new rules. Porn viewing history timeline may be written down in privacy and then brought to the session thereby motivating the addict by looking at the benefits of staying sober as well as not contracting sexual infections after premarital sex.

The counselor needs to assess the clients' readiness to change as suggested by Prochaska and DiClementes' Transtheoretical Model (2001) since this would assist in setting appropriate treatment goals. It is therefore important for the counselor to recognize the addictive nature of media activities, accurately assess the effect that these activities are having on the client and help the client to make a priority to stop these self-destructive activities. 
For anyone to assist the youths in changing the antecedent behavior there is a need to fully recognize the changes, which will be happening to the affected youth. The counselor needs to listen attentively without having any disturbing circumstances as mobile phones. Also, the counselors need not judge the addicts as this would worsen the situation. The lead questions that are made, direct the flow of the counseling session and building relationships. Thus, the counselor will show empathy to the affected youth.

\section{CONCLUSION}

Based on the discussion above, this paper concludes that pornography is a vice that is discouraged by the Scripture. The youth are the most vulnerable with the advent and wide use of the internet. The proposed interventions are to assist the addicts in abstaining from viewing it. The five intervention solutions include a) Youth mentorship, b) Youth Support groups, c) Responsible internet use programs, d) Relationship trust and Respect, and e) Training and Counseling programs. When God created human beings in the beginning, he instructed them to love one another and multiply (Genesis $1: 26)$, and not to view pornography. When people follow God's guidelines, they will always respect one another instead of destroying themselves. Struthers recommended that people should move beyond the line of pornography and appreciate each other as brothers and sisters in Christ. Youths can begin to move beyond objectification and false intimacy to real relationships, which honor the dignity of each person (Barna, 2016). May God help young people to abstain from pornography.

\section{REFERENCES}

[1]. Adventist Review; November 21, 2013.

[2]. Barna Group, "News Conference on Barna's New Study: 'The Porn Phenomenon,”, (January 15, 2016), https://www.barna.org/blog/culture-media/barna-group/pornpress- conference\#.VrS9OrSJndl (accessed June 27, 2016).

[3]. Barna 2016.https://barna-resources.myshopify.com/products/pornphenomenon

[4]. Bimber B. (2000). Measuring the gender gap on the Internet. Social Science Quarterly, 81 (8), 868-876 Bob Davidson, M.Div., M.Ed., LMFT, CSAT Director, Family Institute, P.C.

[5]. Carnes, P. J. (1994). Out of the shadows. Minneapolis, MN: Hazelden Foundation.

[6]. Chiara Sabina, Janis Wolak, and David Finkelhor, "The Nature and Dynamics of Internet Pornography Exposure for Youth," CyberPsychology \& Behavior 11, no. 6 (2008):691-693.

[7]. Chris Denhere \& Pilot Mudhovozi (Great Zimbabwe University). Zimbabwe International Journal of Open \& Distance Learning Volume 1 Number (1) 2011

[8]. City of Anderson Police Department COPS FY 2010 Child Sexual Predator Program Project Description

[9]. Department of Health and Human Services (DHHS) 1998 www.maine.gov/dhhs/ disorders: Relevance for chemical dependency relapse. Substance Use \& Misuse.http://timesofindia.indiatimes.com/topic/pornography

[10]. Duffy, Athena and Dawson, Dave and Das Nair, Roshan (2016) Pornography addiction in adults: a systematic review of definitions and reported impact. Journal of Sexual Medicine. ISSN 1743-6095

[11]. Duffy, Athena (2016), Griffiths 2012, Werry and Billiex 2015. www.sciencedirect.com $>$ article $>$ pii.

[12]. http://doi.org/10.1016/j.abrep.2016.11.003
[13]. Earle, R., Crow, G., \& Osborn, K. (1989). Lonely all the time: Recognizing, understanding, and overcoming sex addiction, for addicts and co-dependents. Endsexualityexploitation.org

[14]. http://www.covenanteyes.com/pornstats/

[15]. https://www.faithandsafety.org/pornography

[16]. http://www.expastors.com/how-many-pastors-are-addicted-toporn-the-stats-are-surprising/

[17]. http://www.juniperresearch.com/press-release/mobile-adult-pr/

[18]. http://www.usatoday.com/story/news/nation/2015/07/14/pornogra phy-public-health-crisis/30152095/

[19]. https://barna-resources.myshopify.com/products/pornphenomenon https://www.barna.com/.../porn-in-the-digital-agenew-research-reveals-10-trends/

[20]. https://www.faithandsafety.org/pornography/2016

[21]. https://en.wikipedia.org/wiki/Sexual relationship

[22]. https://stream.org/aouthor/nancyflory/2016

[23]. https://tolovehonorandvacuum.com/2016/05/women-pornaddiction/

[24]. https://www.biblegateway.com/passage/?search=romans+5\%3a12 \&verson=rsv India Time Journal; Aine Kenny, Travel Editor, April 14, 2017.

[25]. India Times Journal; Dr. Samir Parikk, 2017.

[26]. Internet Pornography by webroot.www.webroot.com>tips-article/2018

[27]. Josh McDowell, Porn Phenomenon Study (July and August 2015)

[28]. Laaser, D., \& Cisney, J. (2007). Spouse recovery. In the American Association of Christian Counselors [Producer], Treating sexual addiction: Professional certificate training program.

[29]. Marni Feuerman. Relationships, Marital Problems. Is Pornography destroying your marriage? 2020. www.verywellmind.com>isporno

[30]. Milrad, R. (1999). Co-addictive recovery: Early recovery issues for spouses of sex addicts. Sexual Addiction \& Compulsivity, 6(2), 125-136.

[31]. Schneider, J. P., \& Irons, R. R. (2001). Assessment and treatment of addictive sexual. Seligman, L., \& Hardenburg, S. A. (2000). Assessment and treatment of paraphilia's. Journal of Counseling \& Development, 78, 107-114. Website, robertweissmsw.com

[32]. Ellen G. White. Letters to Young Lovers. Washington DC, 2001. www.care.org.uk/resources/internet-misuse/what-is-pornography Www.howtobeast.com/porn-addicttion-side-effects-and-how-toquit-porn/ 19 Possible Motives triggering your porn Consumption. www.covenanteyes.com.2016/09.16 